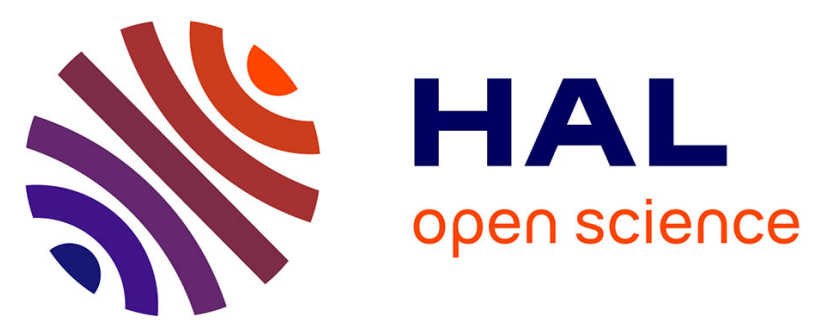

\title{
Association Between Growth Differentiation Factor-15 and Heart Failure Complicating Acute Myocardial Infarction
}

Alexandre Meloux, Luc Rochette, Maud Maza, Florence Bichat, Yves Cottin, Marianne Zeller, Catherine Vergely

\section{To cite this version:}

Alexandre Meloux, Luc Rochette, Maud Maza, Florence Bichat, Yves Cottin, et al.. Association Between Growth Differentiation Factor-15 and Heart Failure Complicating Acute Myocardial Infarction. Cardiology and Cardiovascular Medicine, 2020, 04 (6), pp.773-789. 10.26502/fccm.92920174. hal-03413459

\section{HAL Id: hal-03413459 \\ https://u-bourgogne.hal.science/hal-03413459}

Submitted on 3 Nov 2021

HAL is a multi-disciplinary open access archive for the deposit and dissemination of scientific research documents, whether they are published or not. The documents may come from teaching and research institutions in France or abroad, or from public or private research centers.
L'archive ouverte pluridisciplinaire HAL, est destinée au dépôt et à la diffusion de documents scientifiques de niveau recherche, publiés ou non, émanant des établissements d'enseignement et de recherche français ou étrangers, des laboratoires publics ou privés. 


\title{
Association Between Growth Differentiation Factor-15 and Heart Failure Complicating Acute Myocardial Infarction
}

\author{
Alexandre Meloux ${ }^{1,2}$, Luc Rochette ${ }^{1}$, Maud Maza $^{2}$, Florence Bichat ${ }^{2}$, Yves Cottin ${ }^{1,2}$, \\ Marianne Zeller ${ }^{1}$, Catherine Vergely ${ }^{* 1}$
}

${ }^{1}$ Laboratoire « Physiopathologie et Epidémiologie Cérébro-Cardiovasculaires » (PEC2, EA 7460), Université de Bourgogne-Franche-Comté; UFR des Sciences de Santé; 7 Bd Jeanne d’Arc, 21000, Dijon, France

${ }^{2}$ Department of Cardiology - Dijon Bourgogne University Hospital, France

*Corresponding Author: Catherine Vergely, Laboratoire «Physiopathologie et Epidémiologie CérébroCardiovasculaires » (PEC2, EA 7460), Université de Bourgogne-Franche-Comté; UFR des Sciences de Santé; 7 Bd Jeanne d'Arc, 21000, Dijon, France, Tel: +33-380393292; Fax: +33-380393293; E-mail: cvergely@u-bourgogne.fr

Received: 20 November 2020; Accepted: 03 December 2020; Published: 21 December 2020

Citation: Alexandre Meloux, Luc Rochette, Maud Maza, Florence Bichat, Yves Cottin, Marianne Zeller, Catherine Vergely. Association Between Growth Differentiation Factor-15 and Heart Failure Complicating Acute Myocardial Infarction. Cardiology and Cardiovascular Medicine 4 (2020): 773-789.

\begin{abstract}
Background - Growth differentiation factor-15 (GDF15) is an emerging biomarker in cardiovascular diseases. We aimed to evaluate the association of GDF15 levels at admission with HF occurrence during hospitalization for acute myocardial infarction (AMI).
\end{abstract}

Methods - Our prospective study included all patients admitted from June 2016 to February 2018 for type 1 AMI in the coronary care unit of the DijonBourgogne University Hospital. In-hospital severe heart failure $(\mathrm{HF})$ was defined as Killip class $>2$. Serum levels of GDF15 were obtained from blood samples were taken on admission.

Results - Among the 284 AMI patients, median age was 67 years, and $27 \%$ were women. GDF15 levels were strongly correlated with age and positively correlated with most cardiovascular risk factors (hypertension and diabetes) and inflammation (CRP>3 mg/L). When compared with patients without HF (274/284), GDF15 in patients with inhospital HF (10/284) was more than two times 
higher. Multivariate regression showed that GDF15 $>5,000 \mathrm{ng} / \mathrm{L}$ was an independent marker of HF.

Conclusions - These results suggest that GDF15 could be an integrative biomarker for severe inhospital HF in patients with AMI. Further studies are needed to elucidate the underlying mechanisms linking this cytokine to the development of HF.

Clinical Trial BIOCARDIS - 2016 9205AAO034S02117, from June 2016 to February 2018

Key words: Heart failure; GDF15; AMI, biomarker

\section{Background}

Patients with acute myocardial infarction (AMI) constitute a large and heterogeneous group in terms of severe outcomes and subsequent death. Heart failure $(\mathrm{HF})$ is a frequent complication of $\mathrm{AMI}$ and is associated with high mortality and re-hospitalization rates [1]. HF has an incidence ranging from $14 \%$ to $36 \%$ in AMI [2]. It is characterized by signs such as crackles, lung rales, tachycardia, pulmonary edema, hypotension and electrocardiographic abnormalities. The gravity of HF is indicated through the Killip classification. Both severe (cardiogenic shock) and less severe states of $\mathrm{HF}$ have major adverse consequences and may require specific treatments. Therefore, adequate stratification of patients who are at risk of developing HF in the context of post-AMI may be helpful in estimating prognosis and could be used to guide the cardiologist in clinical decision making. Indeed, cardiac biomarkers such as cardiacTroponin (c-Tn) or N-Terminal pro-Brain Natriuretic Peptide (NT-proBNP) [3,4] currently provide prognostic information for both short- and long-term risk in patients with AMI. However, newer and more specific biomarkers may be helpful in providing additional information that is not provided by classic biomarkers.

Growth differentiation factor 15 (GDF15) is a stressresponsive cytokine which belongs to the transforming growth factor- $\beta$ superfamily, but which finally appears to be closer to the glial cell-derived neurotrophic factors [5]. Although GDF15 is weakly expressed in normal healthy conditions in human tissues (except in the placenta), GDF15 can be produced by many cardiovascular and noncardiovascular cell types under certain pathological situations mainly related to inflammatory stress. Circulating levels of GDF15 reflect acute and chronic cellular stressors which are associated with aging and disease [6,7]. Indeed, in cardiovascular (CV) diseases, GDF15 is an emerging biomarker [8] with strong predictive value for all-cause mortality. In patients with AMI, GDF15 has been recognized as a consistent biomarker of mortality and has been used for long-term follow-up in patients with non STelevation MI [9-13]. In this context, GDF15 provides prognostic information in addition to what is provided by other clinical or biochemical biomarkers including cTnT and NT-proBNP [10, 14-16]. Other data also suggest that GDF15 can be used as a biomarker in acute or chronic HF [17-21]. Initial studies by Kempf et al. led to the emergence of GDF15 as a new biomarker for the risk of death in patients with chronic HF [17]. In patients with acute HF, higher GDF15 was associated with worse prognosis independently of NT-proBNP[18]. In compensated patients, the NT-proBNP/GDF15 ratio distinguished between individuals with preserved and 
reduced ejection fractions [19], and a significant increase in GDF15 in the 6 months following the event was associated in a worse outcome, suggesting that beyond hemodynamic burden (NT-proBNP), inflammatory status (GDF15) may be involved in both HF syndromes [20]. In a meta-analysis including 20,920 HF patients, GDF15 was found to be a strong prognostic biomarker of all-cause mortality [21]. However, there are currently few data concerning the use of GDF15 as a prognostic marker for $\mathrm{HF}$ in a context of AMI.

Therefore, the aim of the present study was to evaluate the prognostic value of GDF15 levels at admission as a predictor of HF occurrence during hospitalization for AMI.

\section{Methods}

\section{Patients}

In this prospective study, all consecutive patients admitted from June 2016 to February 2018 for type 1 AMI in the coronary care unit from the Dijon Bourgogne University Hospital (France) were included in the RICO database (ObseRvatoire des Infarctus de Côte-d'Or). The methods and design of this French regional survey of AMI have been previously described [22]. AMI was diagnosed in accordance with the third universal MI definition [23]. Patients with previous $\mathrm{HF}$ as well as patients with Killip > 2 on admission were excluded. Severe $\mathrm{HF}$ was defined by Killip class > 2. Patients were separated into two groups (no HF group (nHFg) and a HF group ( $\mathrm{HFg})$ ). This study protocol conforms to the ethical guidelines of the Declaration of Helsinki. All of the participants provided consent prior to inclusion, and the Ethics Committee of the University Hospital of Dijon approved the protocol (BIOCARDIS - 2016 - 9205AAO034S02117).

\section{Data collection}

Patient's demographic data, cardiovascular risk factors and history, biological data from blood collected on admission, chronic and acute medications and in-hospital events were collected similar to clinical and biological data as described before [24]. In order to assess the mortality risk, the GRACE score was calculated [25]. Echocardiography was used to determine left ventricular ejection fraction (LVEF).

\section{Determination of serum GDF 15}

Blood samples were collected, on admission, from a vein of the arm, and immediately centrifuged at $4^{\circ} \mathrm{C}$ to separate the serum. The samples were then stored at $-80^{\circ} \mathrm{C}$ until use. Serum GDF15 was measured in duplicate using a commercially available kit (DGD150, R\&D systems, MN). The minimum detectable concentration was $2 \mathrm{ng} / \mathrm{L}$, and the coefficient of variation between duplicates did not exceed $10 \%$.

\section{Statistical analysis}

Statistical analysis was performed as described before [24].

Bivariate linear regression analyses were used to adjust GDF15 with age.

\section{Results}

Baseline characteristics

The study flow chart is presented in Figure 1. 


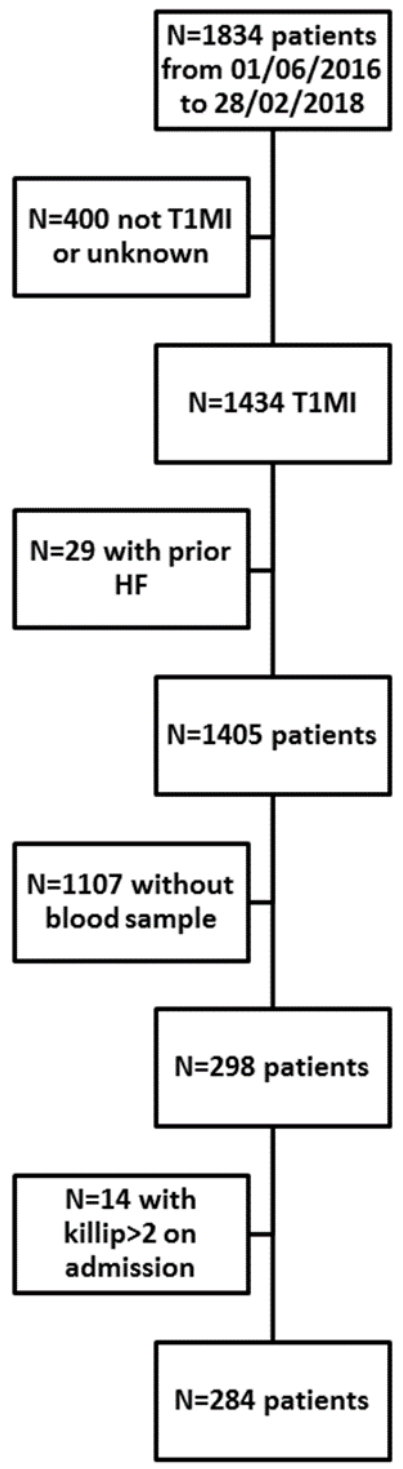

Figure 1: Study flow chart

MI: myocardial infarction; HF: heart failure

Among the 284 included patients, seventy-six (27\%) were female, the median age was 67 years, 66 (23\%) had diabetes and 168 (59\%) had hypertension. Median GDF15 was 1,131 (771-1,811) ng/L. Overall, 10 (4\%) patients presented HF during the hospital stay while the remaining 274 (96\%) patients did not. Table 1 presents the characteristics of patients with and without HF. 


\begin{tabular}{|c|c|c|c|}
\hline & $\mathrm{nHFg}(\mathrm{n}=274)$ & $\operatorname{HFg}(\mathrm{n}=10)$ & $\mathrm{p}$ value \\
\hline \multicolumn{4}{|l|}{ CV risk factors } \\
\hline Age (years) & $67(57-78)$ & $79(71-86)$ & 0.023 \\
\hline Female & $73(27)$ & $3(30)$ & 0.730 \\
\hline BMI $\left(\mathrm{kg} / \mathrm{m}^{2}\right)$ & $26(24-30)$ & $28(24-30)$ & 0.954 \\
\hline Hypertension & $162(59)$ & $6(60)$ & 1.000 \\
\hline Diabetes & $63(23)$ & $3(30)$ & 0.703 \\
\hline Hypercholesterolemia & $105(38)$ & $2(20)$ & 0.329 \\
\hline Family history of CAD & $69(25)$ & $1(10)$ & 0.460 \\
\hline Current smoking & $83(30)$ & $1(10)$ & 0.290 \\
\hline \multicolumn{4}{|l|}{ CV history } \\
\hline $\mathrm{CAD}$ & $45(16)$ & $2(20)$ & 0.673 \\
\hline Stroke & $16(6)$ & $0(0)$ & 1.000 \\
\hline Chronic kidney disease & $13(5)$ & $1(10)$ & 0.402 \\
\hline \multicolumn{4}{|l|}{ Clinical data } \\
\hline LVEF & $55(50-60)$ & $45(36-61)$ & 0.111 \\
\hline HR (bpm) & $76(64-86)$ & $73(57-107)$ & 0.892 \\
\hline $\mathrm{SBP}(\mathrm{mmHg})$ & $142(124-165)$ & $121(110-144)$ & 0.027 \\
\hline DBP (mmHg) & $82(70-94)$ & $75(56-91)$ & 0.233 \\
\hline STEMI & $134(49)$ & $6(60)$ & 0.537 \\
\hline GRACE risk score & $138(115-166)$ & $186(145-192)$ & 0.010 \\
\hline ICU stay length (days) & $3(3-4)$ & $5(5-9)$ & $<0.001$ \\
\hline \multicolumn{4}{|l|}{ Biological data } \\
\hline $\mathrm{CRP} \geq 3 \mathrm{mg} / \mathrm{L}$ & $141(52)$ & $8(80)$ & 0.111 \\
\hline $\begin{array}{l}\text { Creatinine clearance (CKD EPI) } \\
(\mathrm{mL} / \mathrm{min})\end{array}$ & $85(68-97)$ & $69(44-80)$ & 0.020 \\
\hline Peak troponin Ic $(\mathrm{ng} / \mathrm{mL})$ & $15(3-73)$ & $22(1-53)$ & 0.555 \\
\hline NT-proBNP (pg/mL) & $352(84-1,415)$ & $2217(783-8,401)$ & 0.010 \\
\hline Glucose $(\mathrm{mmol} / \mathrm{L})$ & $7(6-8)$ & $7(6-9)$ & 0.483 \\
\hline LDL cholesterol (g/L) & $1.3(1.0-1.5)$ & $0.9(0.6-1.1)$ & 0.019 \\
\hline HDL cholesterol $(\mathrm{g} / \mathrm{L})$ & $0.5(0.4-0.6)$ & $0.6(0.4-0.7)$ & 0.166 \\
\hline Triglycerides (g/L) & $1.2(0.8-1.8)$ & $1.0(0.6-1.3)$ & 0.115 \\
\hline \multicolumn{4}{|l|}{ Chronic medications } \\
\hline Antiplatelet & $23(8)$ & $0(0)$ & 1.000 \\
\hline Aspirin & $63(23)$ & $4(40)$ & 0.253 \\
\hline
\end{tabular}




\begin{tabular}{|l|l|l|l|}
\hline ARB & $55(20)$ & $2(20)$ & 1.000 \\
\hline ACE inhibitors & $53(19)$ & $2(20)$ & 1.000 \\
\hline Statin & $81(30)$ & $3(30)$ & 1.000 \\
\hline Beta-blockers & $72(26)$ & $3(30)$ & 0.727 \\
\hline Acute medications & & & \\
\hline Antiplatelet & $264(96)$ & $8(80)$ & 0.061 \\
\hline Aspirin & $270(98)$ & $8(80)$ & 0.016 \\
\hline ARB & $34(12)$ & $0(0)$ & 0.614 \\
\hline ACE inhibitors & $171(62)$ & $1(10)$ & 0.001 \\
\hline Statin & $253(92)$ & $7(70)$ & 0.043 \\
\hline Beta-blockers & $198(72)$ & $2(20)$ & 0.001 \\
\hline
\end{tabular}

Table 1: Patients' characteristics on admission

Data are expressed as $\mathrm{n}(\%)$ or mean $( \pm$ standard deviation) or median (25th and 75th percentiles) $\mathrm{n}$ : number; BMI: body mass index; CAD: coronary artery disease; LVEF: left ventricular ejection fraction; HR: heart rate; SBP: systolic blood pressure; DBP: diastolic blood pressure; STEMI: ST segment elevation myocardial infarction; GRACE: Global Registry of Acute Coronary Events; ICU: Intensive Care Unit; CRP: C-reactive protein; NTproBNP: N-terminal pro-brain natriuretic peptide; LDL: low density lipoprotein; HDL: high density lipoprotein; ARB: angiotensin II receptor blockers; ACE inhibitors: angiotensin converting enzyme inhibitors.

HF patients were older, but otherwise no differences were reported in $\mathrm{CV}$ risk factors or in $\mathrm{CV}$ history between the two groups. From a clinical point of view, HF patients had lower systolic blood pressure on admission and higher GRACE risk scores. Renal function was more impaired in HF patients (eGFR: 85 [68-97] vs 69 [44-80] mL/min). NT-proBNP levels were higher and LDL-cholesterol levels were lower in HF patients. Median intensive care unit length of stay was significantly higher in patients who developed HF. Concerning all-cause in-hospital mortality, there was no difference between the two groups. There were no differences in long-term treatments, but $\mathrm{HF}$ patients took fewer CV drugs during acute medical care.

Association between GDF15 levels and study variables

Predictors of GDF15 are shown in Table 2. 


\begin{tabular}{|c|c|c|c|}
\hline & Patients $(n=284)$ & GDF15 relative expression or $\mathrm{r}$ & $\mathrm{p}$ value \\
\hline \multicolumn{4}{|l|}{$\mathrm{CV}$ risk factors } \\
\hline Age (years) & $67(57-78)$ & 0.493 & $<0.001$ \\
\hline Female & $76(27)$ & $1,332(942-2,360)$ & 0.008 \\
\hline BMI $\left(\mathrm{kg} / \mathrm{m}^{2}\right)$ & $26(24-30)$ & -0.110 & 0.064 \\
\hline Hypertension & $168(59)$ & $1,378(893-2,316)$ & $<0.001$ \\
\hline Diabetes & $66(23)$ & $1,658(1,070-2,711)$ & $<0.001$ \\
\hline Hypercholesterolemia & $107(38)$ & $1,210(838-2,352)$ & 0.079 \\
\hline Family history of CAD & $70(25)$ & $1,053(773-1,606)$ & 0.100 \\
\hline Current smoking & $84(30)$ & $1,066(667-1,662)$ & 0.075 \\
\hline \multicolumn{4}{|l|}{ CV history } \\
\hline CAD & $47(17)$ & $1,540(1,081-3,091)$ & 0.001 \\
\hline Stroke & $16(6)$ & $1,542(1,073-2,001)$ & 0.171 \\
\hline Chronic kidney disease & $14(5)$ & $2,512(1,426-4,568)$ & $<0.001$ \\
\hline \multicolumn{4}{|l|}{ Clinical data } \\
\hline LVEF & $55(50-60)$ & -0.193 & 0.001 \\
\hline HR (bpm) & $76(64-87)$ & 0.158 & 0.009 \\
\hline SBP (mmHg) & $141(123-165)$ & -0.187 & 0.002 \\
\hline DBP (mmHg) & $82(70-94)$ & -0.286 & $<0.001$ \\
\hline STEMI & $140(49)$ & $1,134(796-1,726)$ & 0.869 \\
\hline GRACE risk score & $139(116-167)$ & 0.545 & $<0.001$ \\
\hline ICU stay length (days) & $3(3-4)$ & 0.129 & 0.030 \\
\hline \multicolumn{4}{|l|}{ Biological data } \\
\hline $\mathrm{CRP} \geq 3 \mathrm{mg} / \mathrm{L}$ & $149(53)$ & $1,334(928-2,293)$ & $<0.001$ \\
\hline Creatinine clearance (CKD EPI) (mL/min) & $83(67-96)$ & 0.269 & $<0.001$ \\
\hline Peak troponin Ic $(\mathrm{ng} / \mathrm{mL})$ & $15(3-70)$ & 0.124 & 0.039 \\
\hline NT-proBNP (pg/mL) & $363(86-1,456)$ & 0.390 & $<0.001$ \\
\hline Glucose $(\mathrm{mmol} / \mathrm{L})$ & $7(6-8)$ & 0.288 & $<0.001$ \\
\hline LDL cholesterol (g/L) & $1.2(0.9-1.5)$ & -0.316 & $<0.001$ \\
\hline HDL cholesterol (g/L) & $0.5(0.4-0.6)$ & -0.059 & 0.326 \\
\hline Triglycerides (g/L) & $1.2(0.8-1.7)$ & -0.089 & 0.139 \\
\hline \multicolumn{4}{|l|}{ Chronic medications } \\
\hline Antiplatelet & $23(8)$ & $1,139(836-2,082)$ & 0.597 \\
\hline Aspirin & $67(24)$ & $1,510(1,037-2,528)$ & 0.003 \\
\hline ARB & $25(20)$ & $1,384(836-2,541)$ & 0.096 \\
\hline
\end{tabular}




\begin{tabular}{|l|l|l|l|}
\hline ACE inhibitors & $55(19)$ & $1,543(1,048-2,684)$ & 0.002 \\
\hline Statin & $84(30)$ & $1,402(986-2,464)$ & 0.001 \\
\hline Beta-blockers & $75(26)$ & $1,435(1,074-2,858)$ & $<0.001$ \\
\hline Acute medications & & & \\
\hline Antiplatelet & $272(96)$ & $1,128(775-1,776)$ & 0.146 \\
\hline Aspirin & $278(98)$ & $1,162(777-1,930)$ & 0.377 \\
\hline ARB & $34(12)$ & $1,163(606-2,361)$ & 0.873 \\
\hline ACE inhibitors & $172(61)$ & $1,071(717-1,588)$ & 0.002 \\
\hline Statin & $260(92)$ & $1,131(761-1,862)$ & 0.086 \\
\hline Beta-blockers & $200(70)$ & $1,192(753-1,964)$ & 0.939 \\
\hline
\end{tabular}

Table 2: Association between GDF15 levels and study variables $(n=284)$.

Data are expressed as $n(\%)$ or median (25th and 75 th percentiles)

n: number; r: correlation coefficient; BMI: body mass index; CAD: coronary artery disease; LVEF: left ventricular ejection fraction; HR: heart rate; SBP: systolic blood pressure; DBP: diastolic blood pressure; STEMI: ST segment elevation myocardial infarction; GRACE: Global Registry of Acute Coronary Events; ICU: Intensive Care Unit; CRP: C-reactive protein; NT-proBNP: N-terminal pro-brain natriuretic peptide; LDL: low density lipoprotein; HDL: high density lipoprotein; ARB: angiotensin II receptor blockers; ACE inhibitors: angiotensin converting enzyme inhibitors

GDF15 levels were significantly associated with age, sex, hypertension and diabetes, prior coronary artery disease and chronic kidney disease. Moreover, GDF15 was positively correlated with heart rate, GRACE risk score, intensive care unit stay length and negatively correlated with LVEF and systolic/diastolic blood pressure. GDF15 showed positive associations with biomarkers such as CRP, creatinine clearance, troponin Ic peak, NT-proBNP, glucose and negative correlation with LDL-cholesterol.

\section{Associations between GDF15 levels and HF}

GDF15 levels were much higher in patients with HF compared to patients without $(1,644 \pm 90$ vs. $4,236 \pm$ $1,103 \mathrm{ng} / \mathrm{L}, \mathrm{p}=0.021$, Figure 2). 


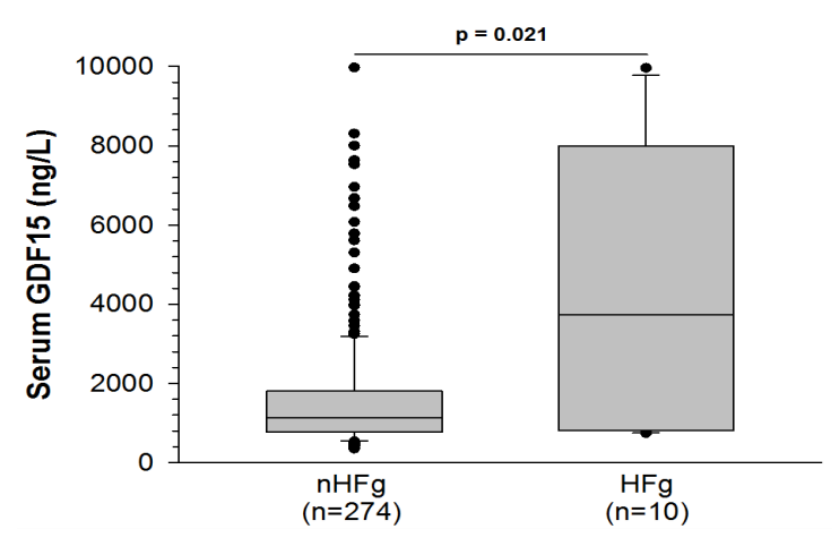

Figure 2: Serum levels of growth differentiation factor 15 (GDF15) in patients who developed heart failure (HFg) and patients who did not develop HF (nHFg) after AMI.

We also analyzed the relationship between the biomarker and $\mathrm{HF}$ severity according to $\mathrm{HF}$ functional class (Killip 1 (no HF) vs Killip 2/3 (moderate HF or pulmonary edema) vs Killip 4 (cardiogenic shock). GDF15 levels increased significantly across the 3 groups $(1,073(718-1,620)$ vs 1497 (988-2,683 vs 7,966 (2,918-9,021))) ng/L. Receiver operating characteristic (ROC) curve analysis identified the cut-off value for GDF15 to estimate $\mathrm{HF}$ risk at $4,981 \mathrm{ng} / \mathrm{L}$; we rounded the curoff to $5,000 \mathrm{ng} / \mathrm{L}$ for more clinical relevance. The area under the curve (AUC) was $0.716(\mathrm{p}=0.021)$ (Figure 3), showing weak sensitivity but high specificity (50\% and 95\%, respectively). Adding GDF15 to the classic clinical biomarkers associated with HF development (i.e. age, LVEF, SBP, and NTproBNP) improved the AUC when compared with the biomarkers alone $(0.817 \pm 0.071$ vs. $0.808 \pm 0.078)$ (Figure 3).

By univariate analysis, age (OR 1.06, 95\% CI 1.011.11; $\mathrm{p}=0.027$ ), systolic blood pressure (OR 0.97, 95\% CI 0.95-1.000; $\mathrm{p}=0.038$ ), LVEF (OR 0.93, 95\% CI $0.89-0.98 ; \mathrm{p}=0.010), \log$ NT-proBNP (OR 3.03;
95\% CI 1.32-6.92; p=0.009) and GDF15 > 5,000 ng/L (OR 20.08; 95\% CI 5.16-78.14; p<0.001) were associated with the onset of HF. There was a gradual relationship between GDF15 and Killip ( $\mathrm{p}<0.001)$. In multivariate analysis, high GDF15 remained associated with onset of $\mathrm{HF}$, after adjustment for confounding factors (Table 3), even beyond traditional HF biological markers such as NTproBNP levels or clinical markers such as LVEF.

The quality index suggested that the model was correct $(-2 \mathrm{LL}=63.308 ; \mathrm{pHL}=0.487 ; \%$ class $=96.5)$. Given the weak statistical power and related low number of events, we further performed 2 separate multivariate models to test the predictive value of GDF15 (model 1: including age, LVEF and SBP; and model 2: age, and Log NT-proBNP). In these 2 models, GDF15 remained a strong estimator of HF ( $\mathrm{p}=0.006$ for model 1 and $\mathrm{p}=0.002$ for model 2). Moreover, the addition of GDF15 significantly improved the performance of all the models, based on -2LL comparison $(\mathrm{p}<0.05)$ (Table 4). 
A

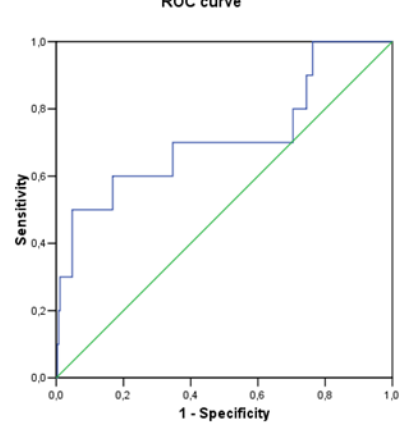

B

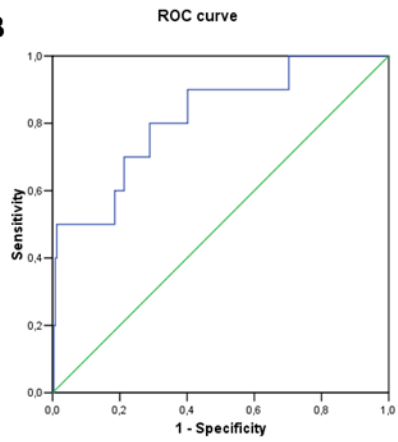

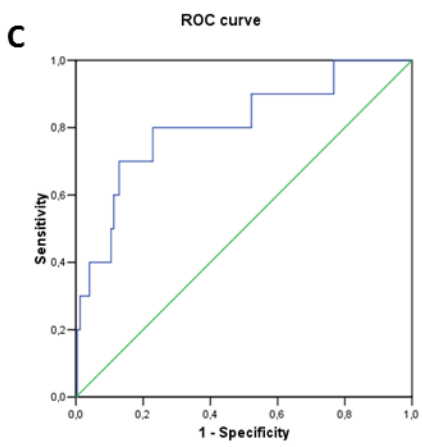

Figure 3: ROC curves for heart failure development including A) GDF15 (AUC $=0.716 \pm 0.100(0.520-0.911)$; $\mathrm{p}=0.021)$; B) clinical biomarkers (age, SBP, NT-proBNP; AUC $=0.808 \pm 0.078(0.656-0.960) ; \mathrm{p}=0.001$ ) and C) GDF15 in addition to clinical biomarkers. $(\mathrm{AUC}=0.817 \pm 0.071(0.678-0.956) ; \mathrm{p}=0.001)$

\begin{tabular}{|l|l|l|l|l|l|l|}
\hline & \multicolumn{2}{|l}{ Univariate } & \multicolumn{2}{l|}{ Multivariate } \\
\hline & OR & $\mathbf{9 5 \%}$ CI & p value & OR & $\mathbf{9 5 \%}$ CI & p value \\
\hline Age, per year & 1.06 & $1.01-1.11$ & 0.027 & 1.03 & $0.98-1.09$ & 0.249 \\
\hline SBP, per mmHg & 0.97 & $0.95-1.000$ & 0.038 & 0.98 & $0.96-1.01$ & 0.247 \\
\hline LVEF, per \% & 0.93 & $0.89-0.98$ & 0.010 & 0.97 & $0.91-1.03$ & 0.294 \\
\hline Log NT-proBNP, per unit & 3.03 & $1.32-6.92$ & 0.009 & 1.12 & $0.42-2.98$ & 0.820 \\
\hline High GDF15, $(>5,000$ vs $\leq 5,000 \mathrm{ng} / \mathrm{L})$ & 20.08 & $5.16-78.14$ & $<0.001$ & 8.43 & $1.57-45.32$ & 0.013 \\
\hline
\end{tabular}

Table 3: Logistic regression analysis to estimate severe HF development in AMI

SBP: systolic blood pressure; LVEF: left ventricular ejection fraction; NT-proBNP: N-terminal pro-brain natriuretic peptide; GDF15: growth differentiation factor 15; OR: odds ratio; CI: confidence interval. 


\begin{tabular}{|c|c|c|c|c|c|c|}
\hline & \multicolumn{2}{|c|}{ Model 1} & \multicolumn{2}{|c|}{ Model 2} & \multicolumn{2}{|c|}{ Model 3} \\
\hline & OR (CI) & $\mathrm{p}$ & OR (CI) & $\mathrm{p}$ & OR (CI) & $\mathrm{p}$ \\
\hline Age, per y & $\begin{array}{l}1.036 \\
(0.984-1.091)\end{array}$ & 0.176 & $\begin{array}{l}1.024 \\
(0.970-1.080)\end{array}$ & 0.390 & $\begin{array}{l}1.042 \\
(0.987-1.100)\end{array}$ & 0.141 \\
\hline $\mathrm{SBP}$, per $\mathrm{mmHg}$ & $\begin{array}{l}0.984 \\
(0.958-1.010)\end{array}$ & 0.223 & $\mathrm{X}$ & & $\begin{array}{l}0.980 \\
(0.954-1.006)\end{array}$ & 0.124 \\
\hline LVEF, per \% & $\begin{array}{l}0.966 \\
(0.907-1.029)\end{array}$ & 0.288 & $\mathrm{X}$ & & $\begin{array}{l}0.951 \\
(0.897-1.009)\end{array}$ & 0.094 \\
\hline GDF15>5000 ng/L & $\begin{array}{l}9.240 \\
(1.884-45.324)\end{array}$ & 0.006 & $\begin{array}{l}10.989 \\
(2.341-51.581)\end{array}$ & 0.002 & $\mathrm{X}$ & \\
\hline $\begin{array}{l}\text { Log NT-proBNP, } \\
\text { per unit }\end{array}$ & $\mathrm{X}$ & & $\begin{array}{l}1.494 \\
(0.593-3.765)\end{array}$ & 0.394 & $\begin{array}{l}1.607 \\
(0.620-4.164)\end{array}$ & 0.329 \\
\hline & $\begin{array}{l}-2 \mathrm{LL}=63.601 ; \\
\% \text { class }=96.6\end{array}$ & $\mathrm{~L}=0.542$ & $\begin{array}{l}-2 \mathrm{LL}=68.457 \\
\% \text { class }=96.4\end{array}$ & $\mathrm{IL}=0.770$ & $\begin{array}{l}-2 \mathrm{LL}=69.026 \\
\% \text { class }=95.8\end{array}$ & $\mathrm{IL}=0.584$ \\
\hline
\end{tabular}

Table 4: Multivariate logistic regression analysis for prediction of in-hospital HF

GDF: Growth differentiation factor; LVEF: Left ventricular ejection fraction; NT-proBNP: N-terminal pro Brain natriuretic peptide; SBP: systolic blood pressure

\section{Discussion}

The present study suggests that GDF15 levels at admission in patients with AMI may help to predict the occurrence of severe HF during hospitalization, in addition to traditional markers.

The stress-responsive GDF15 cytokine has been associated with unfavorable clinical outcomes in both AMI and HF. In STEMI patients, strong correlations have been documented between GDF15 levels and major adverse cardiac events [11]. Moreover, admission GDF15 concentrations are closely related to all-cause mortality in NSTEMI patients [10], which provides prognostic information beyond what is suggested by established clinical and biochemical markers. In 18,876 patients with AMI from the PLATO study, mortality rates were shown to be significantly increased in patients with high circulating GDF15 [26]. Increased concentrations of GDF15 also identified patients at increased risk for adverse left ventricular remodeling [11,27] and recurrent events such as re-hospitalization for congestive HF within two years [28].

In the present study, the median concentration of GDF15 in patients hospitalized for AMI $(1,144$ $\mathrm{ng} / \mathrm{mL}$ ) was slightly lower than in patients with AMI [26] $(1,550 \mathrm{ng} / \mathrm{mL})$, but still in the range of concentrations observed in this population. We observed that in AMI patients, GDF15 circulating 
levels were positively associated with classic cardiovascular risk factors such as age, hypertension, diabetes, chronic kidney disease, coronary artery disease, CRP, NT-proBNP, and C-TnI peak. In patients with stable or acute coronary artery disease, multivariate regression analysis showed that advanced age, diabetes, acute hyperglycemia, and chronic kidney disease were independent predictors of elevated GDF15 levels [29]. Even in patients free of clinically overt cardiovascular diseases, GDF15 was positively associated with age, smoking, antihypertensive treatment, diabetes, and worse kidney function [30]. In elderly community-dwelling individuals, changes in GDF15 levels were also related to male sex, hypertension, diabetes, HF, impaired renal function, and concentrations of NTproBNP [31].

In patients admitted for AMI, HF is a frequent complication that may be present at admission or develop during the hospitalization. It is associated with a substantial increased risk of death by at least 3- to 4-fold [1]. Patients with clinical signs of HF on admission to the hospital are usually older with more frequent recurrent ischemia and diabetes. The development of HF during a hospital stay is usually related to infarct size, mechanical complications, or myocardial stunning. Identifying patients who will develop HF as a complication of AMI is of major importance since they will require tailored treatments. Biomarkers of HF, such as NT-proBNP, are strong independent predictors of risk. However, in the context of AMI, GDF15 can be used to identify patients at high risk at short or long term follow-up [13]. Moreover, in HF patients with preserved or reduced ejection fraction, studies suggest that, in addition to hemodynamic stress evaluated through
NT-proBNP elevation, the inflammatory context related to GDF15 may play an important role [20]. Furthermore, it has been shown that GDF15 can be used as a prognostic biomarker in patients with $\mathrm{HF}$ with preserved ejection fraction [32]. In the present work, we identified admission circulating levels of GDF15 as useful predictors of the occurrence of severe in-hospital HF, in addition to NT-proBNP levels.

So far, little is known about the tissues that produce GDF15 in patients with cardiovascular disease, although GDF15 was shown to be upregulated in the heart after an AMI [33]. However, in patients with non-ischemic dilated cardiomyopathy, the heart does not seem to be an important source of GDF15 production, suggesting that GDF15 might also originate from peripheral tissues [34]. In patients who will develop HF during their hospitalization, higher GDF15 levels may be related to increased infarct size, a hypothesis that is consistent with our observation of a positive correlation between cTnI peak and GDF15 levels. The association with other determinants of in-hospital HF such as myocardial mechanical dysfunction or stunning is not excluded. However, as a biomarker, GDF15 may provide insight that complements the information obtained with traditional clinical or biochemical cardiovascular markers. In the long-term, increased GDF15 concentrations were shown to identify patients at risk of re-hospitalization for new or worsening HF [28], independently of other biomarkers such as hs-CRP and NT-proBNP. GDF15 may reflect non-overlapping disease pathways that contribute to the development of HF after AMI. Notably, changes in GDF15, in contrast to hs-CRP 
variations, are strong predictors of major cardiovascular events [35].

\section{Study limitations}

The small number of patients who developed HF $(n=10)$ and the resulting lack of statistical power limited our ability to draw firm conclusions from our results. Additionally, it was a single-center study and the sensitivity of the test to predict in-hospital HF was low. However, both clinicians and technicians were blinded to the results. Moreover, the association between the biomarker and the event (HF) was significant $(\mathrm{p}=0.021)$, and the result was further supported by both univariate regression analysis $(\mathrm{p}<0.001)$ and AUC $(\mathrm{p}=0.021)$, which persisted even after adjustment for major determinants of $\mathrm{HF}$ $(p=0.013)$. Larger studies are needed to confirm these preliminary findings.

\section{Conclusions}

To conclude, our preliminary study shows that GDF15 could be an integrative biomarker of severe in-hospital HF in patient with AMI. Experimental studies are needed to elucidate the underlying mechanisms linking this cytokine with the development of HF.

\section{Abbreviations}

AMI: acute myocardial infarction

c-Tn: cardiac-Troponin

$\mathrm{CV}$ : cardiovascular

CKD-EPI: Chronic Kidney Disease-Epidemiology Collaboration formula

GDF15: growth differentiation factor-15

$\mathrm{HF}$ : heart failure

LVEF: left ventricular ejection fraction
NT-proBNP: N-Terminal pro-Brain Natriuretic Peptide

RICO: ObseRvatoire des Infarctus de Côte-d'Or SBP: systemic blood pressure

\section{Declarations}

\section{Ethics approval and consent to participate}

This study protocol conforms to the ethical guidelines of the Declaration of Helsinki and was approved by the Ethics Committee of the Dijon University Hospital. Written informed consent was obtained for all participants before inclusion.

\section{Consent to publish}

Not applicable.

\section{Availability of data and material}

The datasets used and/or analyzed during the current study are available from the corresponding author on reasonable request.

\section{Competing interest}

The authors declare to have no competing interests

\section{Funding}

This work was supported by the Dijon Bourgogne University Hospital (clinicians and technician salaries), the Fédération Française de Cardiologie the Association de Cardiologie de Bourgogne (buying of consumables and kits), and by grants from the Agence Régionale de Santé (ARS) de BourgogneFranche-Comté (clinical assistant salaries) and from the Conseil Régional de Bourgogne Franche-Comté (buying of consumables and kits) and from de Agence Nationale de la Recherche (ANR, buying of kits). 


\section{Authors' Contribution}

CV, M.Z. and L.R.: designed and supervised the project, A.M. and $\mathrm{CV}$ wrote the main manuscript, F.B. collected patient's data, YC: gave scientific guidance; AM: performed biological analysis, A.M., M.Z. and M.M.: performed statistical analysis and prepared figures and tables. All authors reviewed the manuscript.

\section{Acknowledgments}

The authors thank Suzanne Rankin for English revision of the manuscript, and Ivan Porcherot and Morgane Lainé for providing technical assistance.

\section{References}

1. Bahit MC, Kochar A, Granger CB. Post-myocardial infarction heart failure. JACC: Heart Failure 6 (2018): 179-186.

2. Hellermann JP, Jacobsen SJ, Gersh BJ, et al. Heart failure after myocardial infarction: a review. The American Journal of Medicine 113 (2002): 324330 .

3. Steinhart B, Thorpe KE, Bayoumi AM, et al. Improving the diagnosis of acute heart failure using a validated prediction model. Journal of the American College of Cardiology 54 (2009): 1515-1521.

4. McKie PM, Burnett Jr JC. NT-proBNP: The Gold Standard Biomarker in Heart Failure. Journal of the American College of Cardiology 68 (2016): 24372439.
5. Emmerson PJ, Wang F, Du Y, et al. The metabolic effects of GDF15 are mediated by the orphan receptor GFRAL. Nature Medicine 23 (2017): 1215.

6. Kahli A, Guenancia C, Zeller M, et al. Growth differentiation factor-15 (GDF15) levels are associated with cardiac and renal injury in patients undergoing coronary artery bypass grafting with cardiopulmonary bypass. PloS One 9 (2014): e105759.

7. Guenancia C, Kahli A, Laurent G, et al. Pre-operative growth differentiation factor 15 as a novel biomarker of acute kidney injury after cardiac bypass surgery. International Journal of Cardiology 197 (2015): 66-71.

8. Wollert KC, Kempf T, Wallentin L. Growth differentiation factor 15 as a biomarker in cardiovascular disease. Clinical Chemistry 63 (2017): 140-151.

9. Wollert KC, Kempf T, Lagerqvist B, et al. Growth differentiation factor 15 for risk stratification and selection of an invasive treatment strategy in non STelevation acute coronary syndrome. Circulation 116 (2007): 1540-1548.

10. Wollert KC, Kempf T, Lagerqvist B, et al. Growth differentiation factor 15 for risk stratification and selection of an invasive treatment strategy in non STelevation acute coronary syndrome. Circulatio 116 (2007): 1540-1548.

11. Eitel I, Blase P, Adams V, et al. Growth-differentiation factor 15 as predictor of mortality in acute 
reperfused ST-elevation myocardial infarction: insights from cardiovascular magnetic resonance. Heart 97 (2011): 632-640.

12. Widera C, Pencina MJ, Meisner A, et al. Adjustment of the GRACE score by growth differentiation factor 15 enables a more accurate appreciation of risk in non-ST-elevation acute coronary syndrome. European Heart Journal 33 (2012): 1095-1104.

13. Damman P, Kempf T, Windhausen F, et al. Growth-differentiation factor 15 for long-term prognostication in patients with non-ST-elevation acute coronary syndrome: an Invasive versus Conservative Treatment in Unstable coronary Syndromes (ICTUS) substudy. International Journal of Cardiology 172 (2014): 356-363.

14. Khan $\mathrm{SQ}, \mathrm{Ng} \mathrm{K}$, Dhillon $\mathrm{O}$, et al. Growth differentiation factor-15 as a prognostic marker in patients with acute myocardial infarction. European Heart Journal 30 (2009): 1057-1065.

15. Kempf T, Björklund E, Olofsson S, et al. Growth-differentiation factor-15 improves risk stratification in STsegment elevation myocardial infarction. European Heart Journal 28 (2007): 2858-2865.

16. Schaub N, Reichlin T, Twerenbold R, et al. Growth differentiation factor-15 in the early diagnosis and risk stratification of patients with acute chest pain. Clinical Chemistry 58 (2012): 441-449.
17. Kempf T, von Haehling S, Peter T, et al. Prognostic utility of growth differentiation factor-15 in patients with chronic heart failure. Journal of the American College of Cardiology 50 (2007): 1054-1060.

18. Bettencourt P, Ferreira-Coimbra J, Rodrigues $\mathrm{P}$, et al. Towards a multimarker prognostic strategy in acute heart failure: a role for GDF-15. ESC Heart Failure 5 (2018): 1017-1022.

19. Santhanakrishnan R, Chong JP, Ng TP, et al. Growth differentiation factor 15 , ST2, high-sensitivity troponin T, and Nterminal pro brain natriuretic peptide in heart failure with preserved vs. reduced ejection fraction. European Journal of Heart Failure 14 (2012): 1338-1347.

20. Chan MM, Santhanakrishnan R, Chong JP, et al. Growth differentiation factor 15 in heart failure with preserved vs. reduced ejection fraction. European Journal of Heart Failure 18 (2016): 8188.

21. George M, Jena A, Srivatsan V, et al. GDF 15-a novel biomarker in the offing for heart failure. Current Cardiology Reviews 12 (2016): 37-46.

22. Zeller M, Steg PG, Ravisy J, et al. Relation between body mass index, waist circumference, and death after acute myocardial infarction. Circulation 118 (2008): 482-490.

23. Thygesen K, Alpert JS, Jaffe AS, et al. Third universal definition of myocardial 
infarction. Circulation 126 (2012):

2020-2035.

24. Meloux A, Rochette L, Maza M, et al. Growth Differentiation Factor-8 (GDF8)/Myostatin Is a Predictor of Troponin I Peak and a Marker of Clinical Severity after Acute Myocardial Infarction. Journal of Clinical Medicine 9 (2020): 116.

25. Granger CB, Goldberg RJ, Dabbous O, et al. Predictors of hospital mortality in the global registry of acute coronary events. Archives of Internal Medicine 163 (2003): 2345-2353.

26. Hagström E, James SK, Bertilsson M, et al. Growth differentiation factor-15 level predicts major bleeding and cardiovascular events in patients with acute coronary syndromes: results from the PLATO study. European Heart Journal 37 (2016): 1325-1333.

27 Dominguez-Rodriguez A, AbreuGonzalez P, Avanzas P. Relation of growth-differentiation factor 15 to left ventricular remodeling in ST-segment elevation myocardial infarction. The American Journal of Cardiology 108 (2011): 955-958.

28. Bonaca MP, Morrow DA, Braunwald E, et al. Growth differentiation factor15 and risk of recurrent events in patients stabilized after acute coronary syndrome: observations from PROVE IT-TIMI 22. Arteriosclerosis, Thrombosis, and Vascular Biology 31 (2011): 203-210.
29. Farhan S, Freynhofer MK, Brozovic I, et al. Determinants of growth differentiation factor 15 in patients with stable and acute coronary artery disease. A prospective observational study. Cardiovascular Diabetology 15 (2016): 60 .

30. Ho JE, Mahajan A, Chen MH, et al. Clinical and genetic correlates of growth differentiation factor 15 in the community. Clinical Chemistry 58 (2012): 1582-1591.

31. Eggers KM, Kempf T, Wallentin L, et al. Change in growth differentiation factor 15 concentrations over time independently predicts mortality in community-dwelling elderly individuals. Clinical Chemistry 59 (2013): 1091-1098.

32. Izumiya Y, Hanatani S, Kimura Y, et al. Growth differentiation factor-15 is a useful prognostic marker in patients with heart failure with preserved ejection fraction. Canadian Journal of Cardiology 30 (2014): 338-344.

33. Kempf T, Eden M, Strelau J, et al. The transforming growth factor- $\beta$ superfamily member growthdifferentiation factor-15 protects the heart from ischemia/reperfusion injury. Circulation Research 98 (2006): 351360 .

34. Lok SI, Winkens B, Goldschmeding R, et al. Circulating growth differentiation factor-15 correlates with myocardial fibrosis in patients with non-ischaemic dilated cardiomyopathy and decreases 
rapidly after left ventricular assist device support. European Journal of Heart Failure 14 (2012): 1249-1256.

35. Dominguez-Rodriguez A, AbreuGonzalez P, Hernandez-Baldomero IF, et al. Change in growth differentiation factor 15, but not C-reactive protein, independently predicts major cardiac events in patients with non-ST elevation acute coronary syndrome. Mediators of Inflammation 2014 (2014).

(c) (1) ${ }_{\text {BY }}^{\text {This article is an open access article distributed under the terms and conditions of the }}$ 